\title{
Influence of Clay Fraction and Mineral Composition on Unsaturated Characteristics of Cohesive Foundation Soil in Airports
}

\author{
Jun Feng $\mathbb{D}^{1,2}$ and Guangze Zhang $^{3}$ \\ ${ }^{1}$ School of Airport Engineering and Transportation Management, Civil Aviation Flight University of China, \\ Guanghan 618307, China \\ ${ }^{2}$ School of Resources and Civil Engineering, Northeastern University, Shenyang 110004, China \\ ${ }^{3}$ China Railway Eryuan Engineering Group. Co. Ltd, Chengdu 610031, China
}

Correspondence should be addressed to Jun Feng; sckid1987@163.com

Received 11 May 2021; Revised 11 September 2021; Accepted 27 September 2021; Published 21 October 2021

Academic Editor: Xudong Zhang

Copyright (c) 2021 Jun Feng and Guangze Zhang. This is an open access article distributed under the Creative Commons Attribution License, which permits unrestricted use, distribution, and reproduction in any medium, provided the original work is properly cited.

Taking unsaturated clay foundation soil of an airport project in Hefei as the research object, the effects of particle gradation and mineral composition on the unsaturated soil properties were analyzed through two kinds of tests. The results show that there is a good correlation between the residual water content and the clay fraction or silt fraction content in the grading, and the residual water content has a significant positive linear correlation with the clay fraction content, but a negative linear correlation with the silt fraction content. Residual matric suction has a nonlinear correlation with clay fraction or silt fraction content in gradation, which has a significant nonlinear negative correlation with clay fraction content and a positive nonlinear correlation with silt fraction content. The residual water content and the residual matric suction have obvious linear relationship with the content of montmorillonite but have no obvious correlation with the content of illite. The water-storage coefficient of unsaturated airfield foundation soil decreases exponentially with the increase of clay content and montmorillonite content.

\section{Introduction}

For clay soil, the difference in physical and chemical properties such as particle size distribution and mineral composition is often an important factor affecting the selection of macroscopic mechanical parameters. Liu et al. used three kinds of soil particles with different gradations to conduct large-scale indoor direct shear tests with geogrid and geotextiles, respectively, and the study showed that the soil particle gradations would affect the shear characteristics of the interface between soil particles and geosynthetic materials and then affect the dilatation coefficient of the interface [1]. Fan et al. has carried on the corresponding research, which showed that the clayey soil total mineral composition, chemical composition determines the dispersivity of the soil mass.; the difference between soil will affect the macroscopic mechanical parameters [2]. For unsaturated soil, Zhi-qing et al., Lu et al., Liu et al., Feng et al., Liang et al., and Zheng carried out a series of related tests using unsaturated soil triaxial apparatus [3-10]. The influence of mineral composition, plasticity index, pore structure, water content, and stress state on the soil-water characteristic curve of unsaturated expansive soil is systematically analyzed. Their research shows that there is a kind of residual matric suction in unsaturated soil, and there is a certain correlation between the residual matric suction and the residual water content of the soil, and the unsaturated characteristics of the soil 
are affected by the residual matric suction and residual water content. Zhang et al. pointed out through experiments that, under high suction, matric suction was not only affected by water content but also affected by clay content and mineral composition [11]. Wen and $\mathrm{Hu}$ found through research that particle size had a weak influence on residual matric suction, and there was a certain correlation between residual matric suction and the ratio of coarse and fine clay content [12]. It can be seen from the above researches that the physical and chemical properties of soils play an important role in the macro- and microengineering characteristics of unsaturated soils.

It can be seen from the current researches that most of the researches tend to be on unsaturated soils under static load, and there are relatively few researches on unsaturated soils under dynamic and static load of aircraft wheel load. Therefore, the study of unsaturated soil in airport engineering has important engineering application value to the design and construction of an airport.

In view of this, the clay foundation soil of an airport project in Hefei is taken as the research object, and the effects of particle gradation and mineral composition on the unsaturated soil properties are analyzed, respectively, through two kinds of tests.

\section{Data and Method}

2.1. Soil Samples and Experiment Preparation. Particle size distribution mainly affects the change of matric suction inside soil and then affects its macroscopic engineering characteristics. Figure 1 shows the sampling diagram of the undisturbed soil sample on-site.

Three different gradations of remolded soil samples were prepared according to the content of clay particles and silt particles, and ring cutter samples with a diameter of $61.8 \mathrm{~mm}$ and a height of $20 \mathrm{~mm}$ were made. The soil-water characteristic curves were analyzed by an unsaturated soil pressure plate (Figure 2), and then, the influence characteristics of clay and silt contents on the internal matric suction were studied. The basic physical properties of remolded soil samples after preparation are shown in Table 1, and the soilwater characteristic curves of the three graded foundation soils are shown in Figure 3.

The influence of matric suction on the soil-water characteristic curve is mainly manifested in two aspects, namely, residual water content and residual matric suction. According to the method of Fredlund and Xing [13-15], the residual water content and residual matric suction of foundation soil with different gradations can be obtained according to soil-water characteristic curves. Residual water content is a measure of the amount of "immovable" water contained in the medium. These small amounts of residual water are tightly attached to the surface of the medium particles in the form of thin films or independent water rings and can no longer actually move. It is related to the fine pore distribution of medium, mineral composition, and chemical composition of pore water. The values in the table are calculated from the eigenvalues

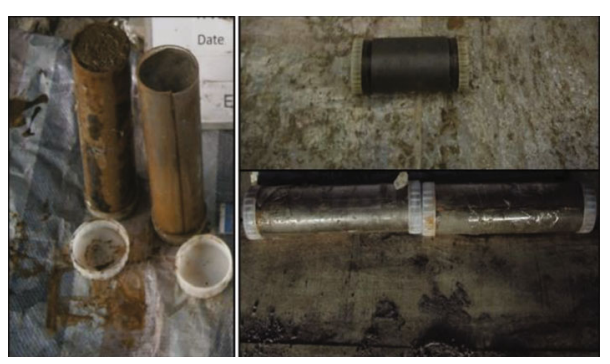

FIGURE 1: Sampling diagram of undisturbed soil sample on-site.

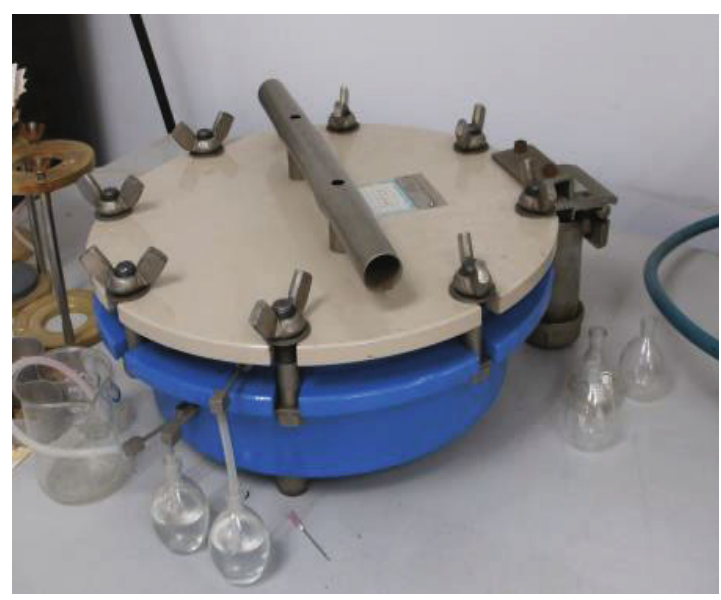

FIGURE 2: Unsaturated soil pressure plate.

of the curves and then plugged into the relevant theoretical formulas. It has been shown in Table 2 .

2.2. Theoretical Analysis Method. The van Genuchten model is the most popular empirical model for fitting the SWCC. This was proposed by van Genuchten in 1980, which adopted the association of the efficient saturation level with pressure head according to initial Mualem's equation [16]. At the same time, Song and colleagues assessed those welcome SWCC models, and according to their results, the van Genuchten (1980) model represented the optimal method for estimating SWCC [17]. Therefore, in the present study, the SWCC was estimated through van Genuchten's equation (1980) by adopting water flow and matric suction results. Based on the van Genuchten SWCC model (1980), the effective volumetric water content $\theta_{\mathrm{e}}$ and matric suction can be described, as follows:

$$
\theta_{\mathrm{e}}=\left[\frac{1}{1+\left\{\alpha\left(u_{a}-u_{w}\right)\right\}^{n}}\right]^{1-1 / n},
$$

where $\theta_{\mathrm{e}}$ represents the effective volumetric water content; $\alpha=1 / u_{b}, u_{b}$ represents the air-entry pressure, and $n$ represents the pore-size spectrum number. In general, the larger the value of $n$, the wider the range of pore sizes. Depending 
TABLE 1: Physical properties of remolded unsaturated soils.

\begin{tabular}{lccccccc}
\hline $\begin{array}{l}\text { Serial } \\
\text { number }\end{array}$ & $\begin{array}{c}\text { Dry density } \\
\rho_{\mathrm{d}}\left(\mathrm{g} / \mathrm{cm}^{3}\right)\end{array}$ & $\begin{array}{c}\text { Void ratio } \\
\text { A\# }\end{array}$ & $\begin{array}{c}\text { Liquid limit } \\
(\%)\end{array}$ & $\begin{array}{c}\text { Plastic limit } \\
(\%)\end{array}$ & $\begin{array}{c}\text { Plasticity } \\
\text { index }\end{array}$ & $\begin{array}{c}\text { Grain composition (mm) and its content (\%) } \\
\text { Clay fraction }(< \\
0.005)\end{array}$ & $\begin{array}{c}\text { Silt fraction } \\
(0.005 ~ 0.075)\end{array}$ \\
\hline B\# & 1.62 & 0.74 & 37 & 18 & 19 & 21.46 & 76.32 \\
C\# & 1.48 & 0.82 & 38 & 18 & 20 & 27.78 & 67.24 \\
\hline
\end{tabular}

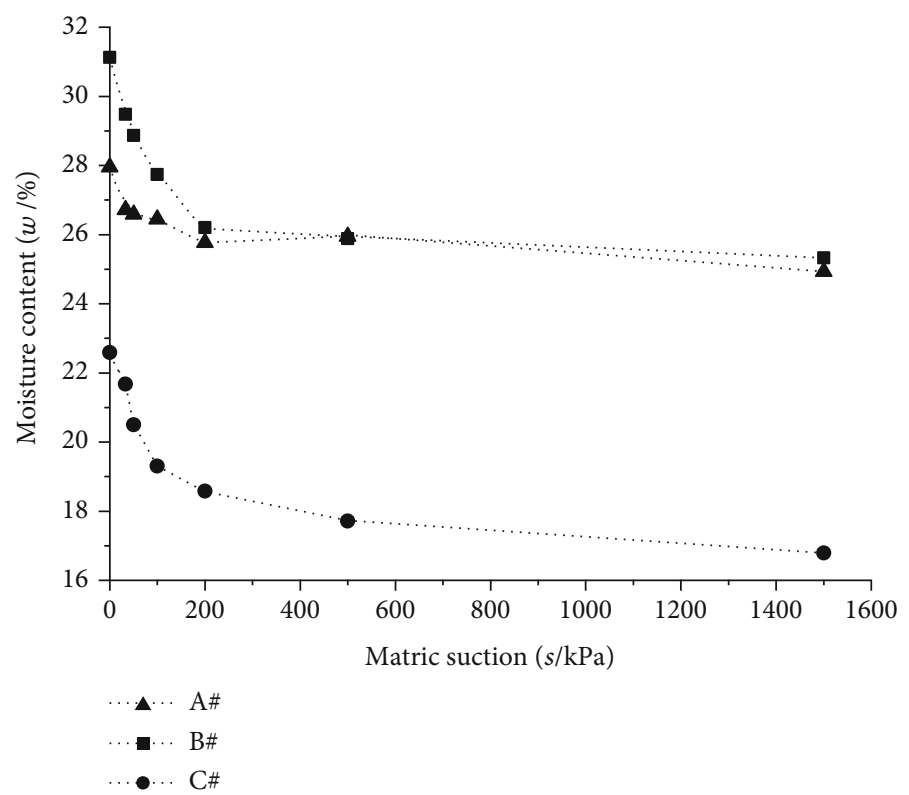

FIGURE 3: SWCC of three kinds of soil with different gradations.

TABLE 2: Characteristic parameter of SWCC.

\begin{tabular}{lcc}
\hline $\begin{array}{l}\text { Serial } \\
\text { number }\end{array}$ & $\begin{array}{c}\text { Residual moisture } \\
\text { content }(\%)\end{array}$ & $\begin{array}{r}\text { Residual matric suction } \\
(\mathrm{kPa})\end{array}$ \\
\hline $\mathrm{A \#}$ & 15.70 & 42.38 \\
$\mathrm{~B} \#$ & 17.98 & 38.24 \\
$\mathrm{C \#}$ & 14.24 & 50.36 \\
\hline
\end{tabular}

on the geologic conditions and climatic conditions of soil formation, soils with a wide range of particle sizes may lead to a wide range of pore sizes, such as those typical for loess soils and expansive soils.

Since the SWCC curve of the studied soil presents an atypical " $S$ " shape, the problem it faces is that the residual water content cannot be accurately obtained through the curve. Residual moisture content represents the moisture content that can be held by the soil at very high matric suction. In the extreme case, when the soil is nearly completely dry, the water content is 0 and the residual matric suction is close to infinity. Based on the above analysis, the residual water content of the cohesive foundation soil in the test section was considered 0 and the residual matric suction $\infty$, and then, the modified three-parameter van Genuchten model was obtained:

$$
\theta=\frac{\theta_{s}}{\left[1+(\alpha \psi)^{n}\right]^{m}},
$$

where $a, n$, and $m$ are the parameters of the modified model, respectively. The modified van Genuchten model was used to fit the experimental results, and the fitting results are shown in Figure 4.

\section{Results}

\subsection{Effect of Particle Size on Unsaturated Properties}

3.1.1. Influence Characteristics on Residual Water Content. Table 2 can be obtained in unsaturated residual moisture content with the grading of foundation soil and the changes of clay or silt content as shown in Figure 5; it can be seen that the residual moisture content and gradation of clay or silt content have a good correlation, which shows a significant linear positive correlation with the clay content and the present linear negative correlation with silt content. 


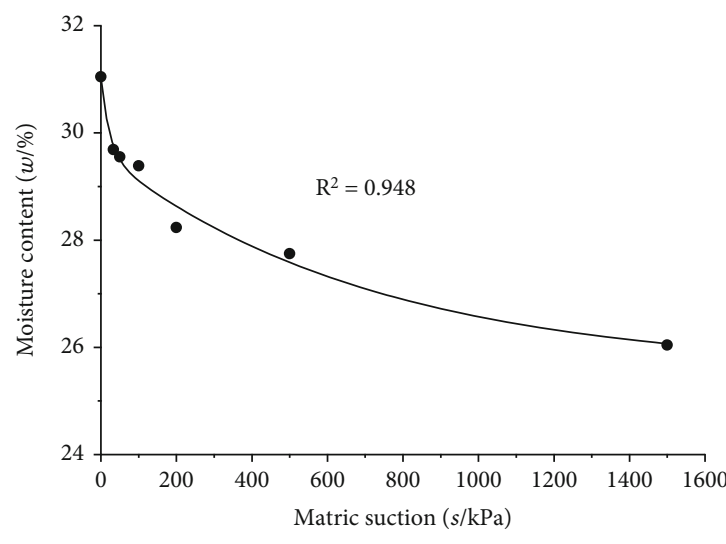

- Experimental value

_ Modified van genuchten model

(a) Clay fraction content of $10 \%$

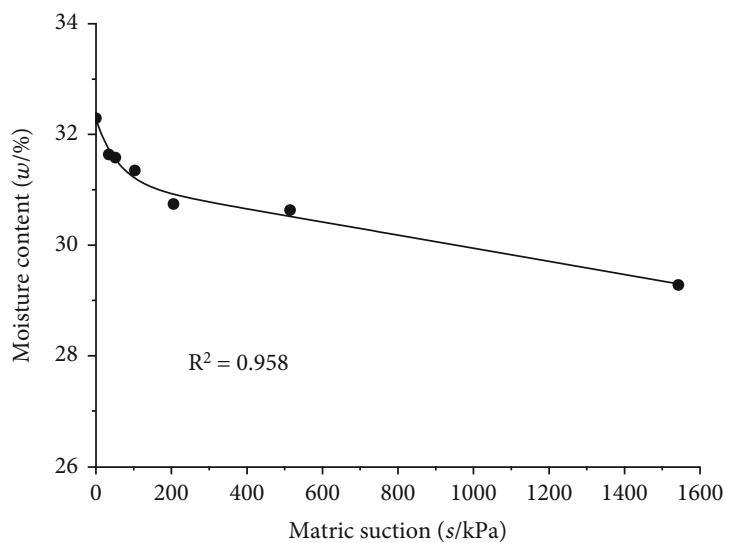

- Experimental value

- Modified van genuchten model

(c) Clay fraction content of $40 \%$

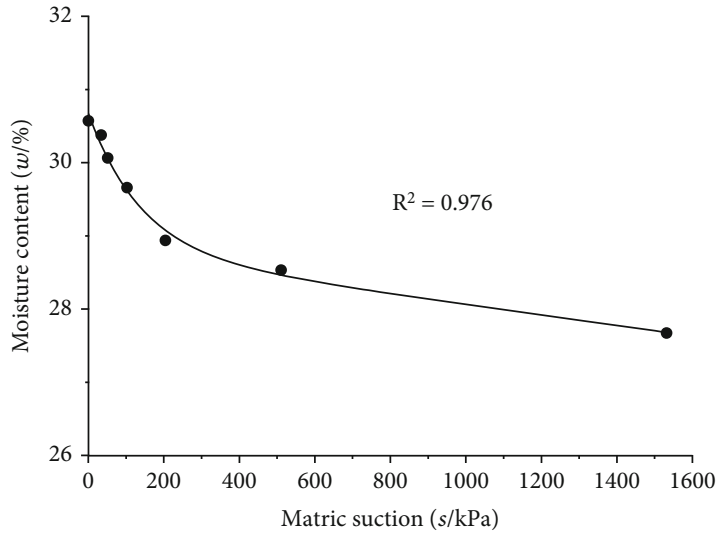

- Experimental value

- Modified van genuchten model

(b) Clay fraction content of $20 \%$

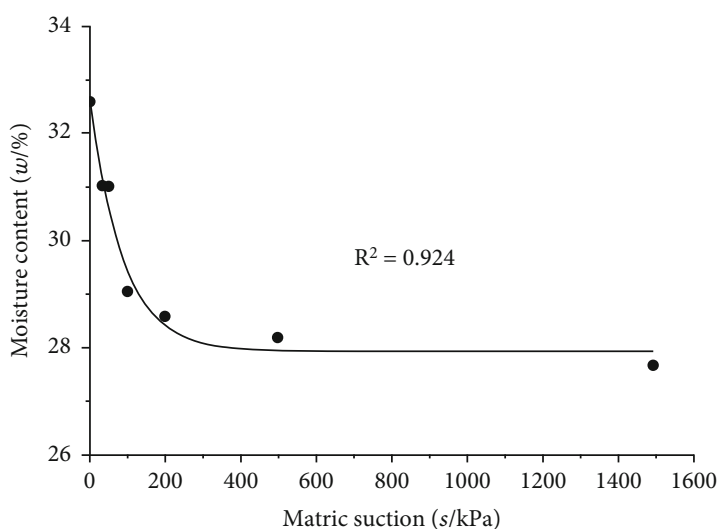

- Experimental value

_ Modified van genuchten model

(d) Clay fraction content of $50 \%$

FIgURE 4: SWCC curves of different clay fraction contents.

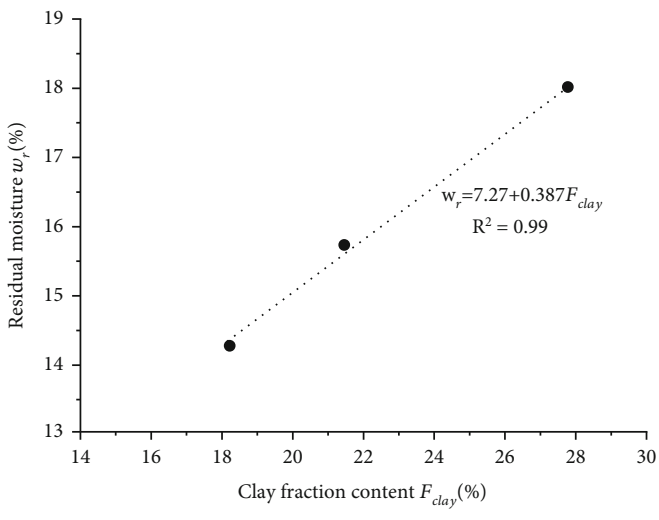

- Experimental data

. Fitting curve

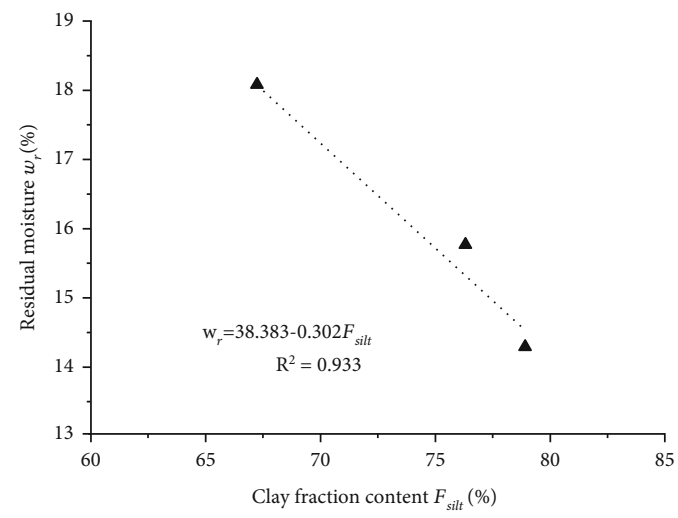

- Experimental data

Fitting curve

(a) Clay fraction

(b) Silt fraction

FIGURE 5: Relationship between residual water content and gradation. 


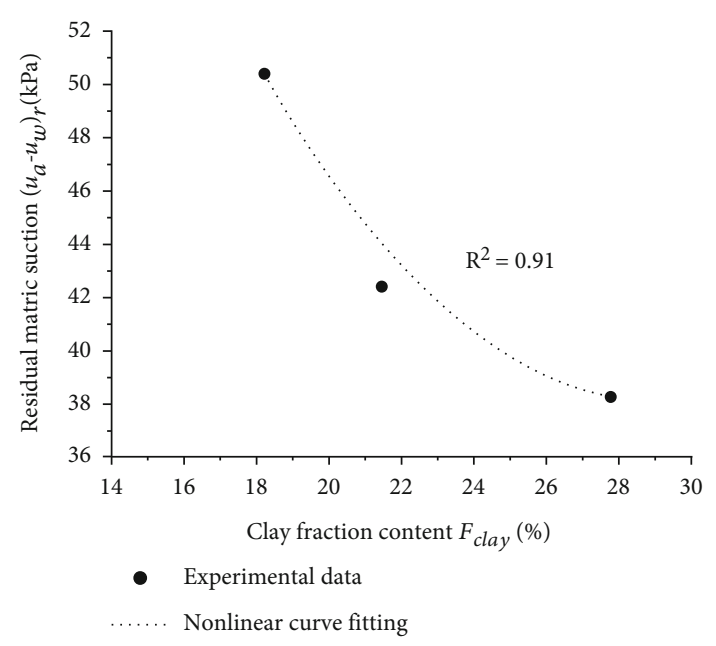

(a) Clay fraction

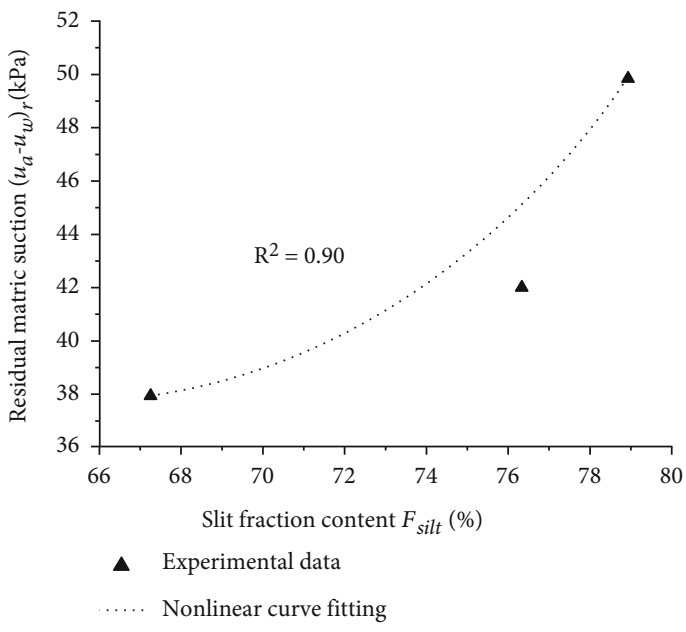

(b) Silt fraction

FIGURE 6: Relationship between residual metric suction and gradation.

TABLE 3: Soil sample with different clay mineral contents.

\begin{tabular}{lccc}
\hline Serial number & Montmorillonite (\%) & Illite (\%) & Chlorite (\%) \\
\hline $1 \#$ & 45 & 4 & 2 \\
$2 \#$ & 26 & 7 & 0 \\
$3 \#$ & 15 & 2 & 0 \\
\hline
\end{tabular}

3.1.2. Influence Characteristics on Residual Matric Suction. Figure 6 shows the relationship between the residual matric suction in unsaturated foundation soil and the content of clay or silt in gradation. It can be seen that the residual matric suction has a nonlinear change relationship with the content of clay or silt in gradation, showing a nonlinear negative correlation with clay content and a nonlinear positive correlation with the content of silt.

3.2. Influence of Mineral Composition on Unsaturated Characteristics. Table 3 shows the content distribution of montmorillonite and illite in remolded samples. Since clay minerals have the greatest influence on the unsaturated engineering characteristics of clay foundation soil, this paper mainly analyzes the composition of clay minerals in foundation soil.

As can be seen from Table 3, among the clay minerals, the content of montmorillonite is the most abundant, followed by illite, and chlorite can only be detected in three depth ranges, and the content is very low. Therefore, this paper only studies the effects of montmorillonite and illite on the characteristics of unsaturated soils. Figure 7 shows the vertical distribution of montmorillonite and illite in foundation soil.

Three depths of foundation soil with greatly different clay mineral compositions in the test site were selected as the test objects. The foundation soil at each depth was dried and prepared into samples with the same initial water content $(18 \%)$ and dry density $\left(1.65 \mathrm{~g} / \mathrm{cm}^{3}\right)$. The soil-water characteristic curves of each remolded sample were ana- lyzed, as shown in Figure 8. The corresponding parameters were obtained by the van Genuchten model, as shown in Table 4.

3.2.1. Influence Characteristics on Residual Water Content. According to Table 5, the relationship between the content of clay minerals and residual water content in unsaturated foundation soil can be obtained, as shown in Figure 9. As can be seen from Figure 7, residual water content is significantly positively correlated with the content of montmorillonite, while there is no significant correlation with the change of illite content. Due to the large distance between adjacent crystal cells, weak connection, and easy infiltration of water molecules, montmorillonite can easily form fine clay particles, which increases the specific surface area and enhances hydrophilicity. When the content of montmorillonite is high in the clay soil, the corresponding residual water content increases accordingly.

3.2.2. Influence Characteristics of Residual Matric Suction. Figure 10 shows the influence of clay mineral content on the residual matric suction. It can be seen from the figure that the residual matric suction also presents a significant positive correlation with the content of montmorillonite, while there is no significant correlation with the change of illite content.

\subsection{Influence on Soil-Water Characteristic Curve}

\subsubsection{Influence of Clay Content on Soil-Water Characteristic} Curve. Figure 9 shows the unsaturated SWCC curve of airport foundation soil considering different clay contents. As can be seen from the figure, when the matric suction is the same, the soil moisture content decreases with the increase of clay particle content. Although the moisture content of soil decreases with the increase of matric suction under different clay content conditions, the curve is slightly different due to the different clay contents. The van Genuchten model 


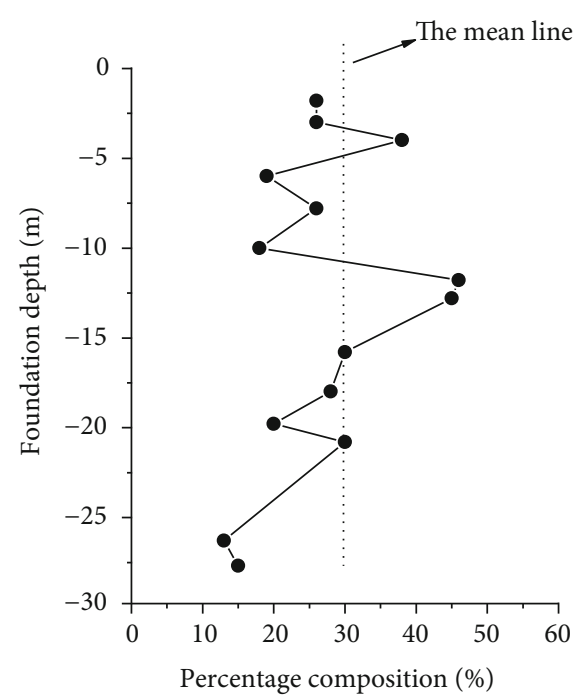

(a) Montmorillonite

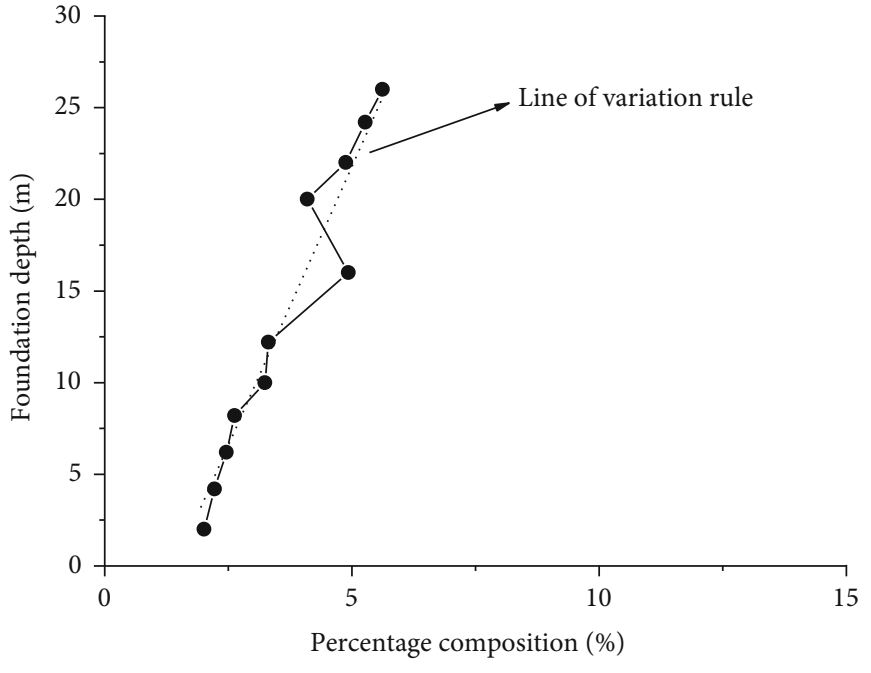

(b) Illite

FIgURE 7: Distribution of montmorillonite and illite along foundation depth.

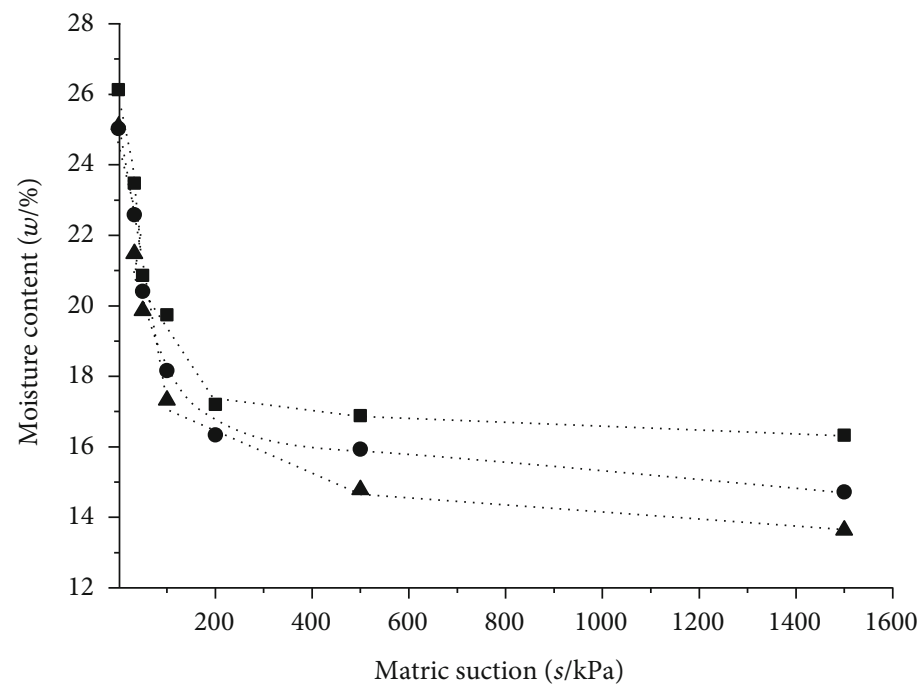

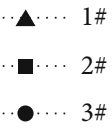

Figure 8: SWCC of three kinds of foundation soil.

TABLE 4: Characteristic parameter of SWCC.

\begin{tabular}{lcc}
\hline $\begin{array}{l}\text { Serial } \\
\text { number }\end{array}$ & $\begin{array}{c}\text { Residual moisture } \\
\text { content } w_{r}(\%)\end{array}$ & $\begin{array}{c}\text { Residual matric suction } \\
\left(u_{a}-u_{w}\right)_{r}(\mathrm{kPa})\end{array}$ \\
\hline $1 \#$ & 16.325 & 69.364 \\
$2 \#$ & 14.723 & 64.762 \\
$3 \#$ & 13.635 & 57.865 \\
\hline
\end{tabular}

Table 5: Modified van Genuchten model fitting parameters for different clay fraction contents.

\begin{tabular}{lccc}
\hline Clay fraction content $w^{\prime}(\%)$ & $1 / a$ & $n$ & $m$ \\
\hline 10 & 25.02 & 6.440 & 0.832 \\
20 & 35.50 & 6.100 & 0.824 \\
40 & 41.88 & 5.126 & 0.802 \\
50 & 41.56 & 3.764 & 0.638 \\
\hline
\end{tabular}




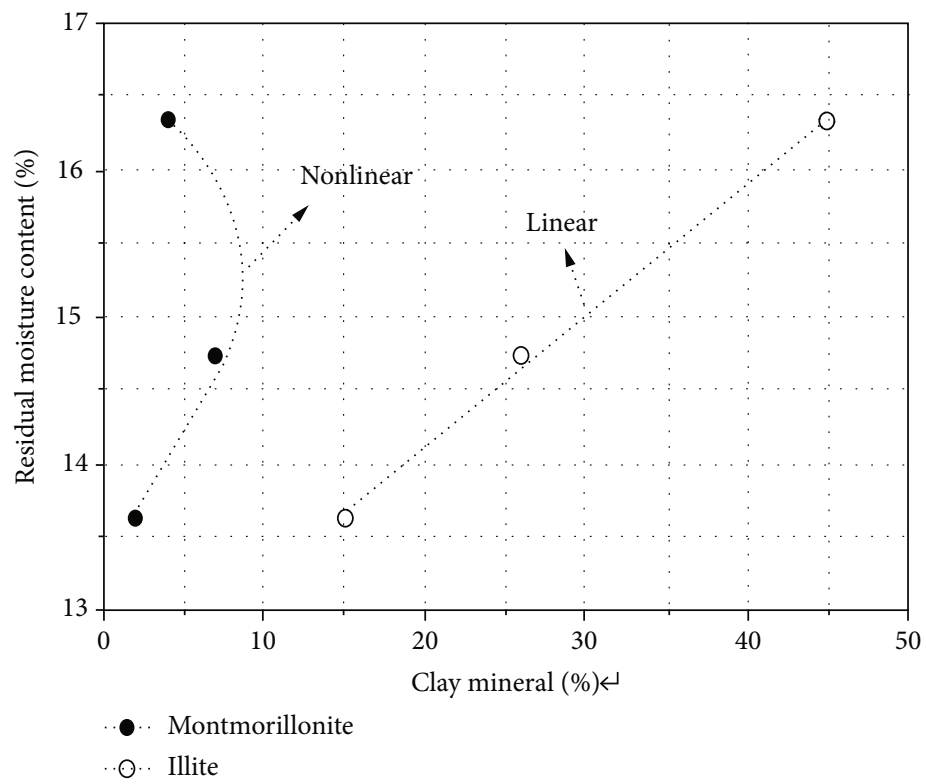

FIgURE 9: Relationship between residual water content and content of clay fraction.

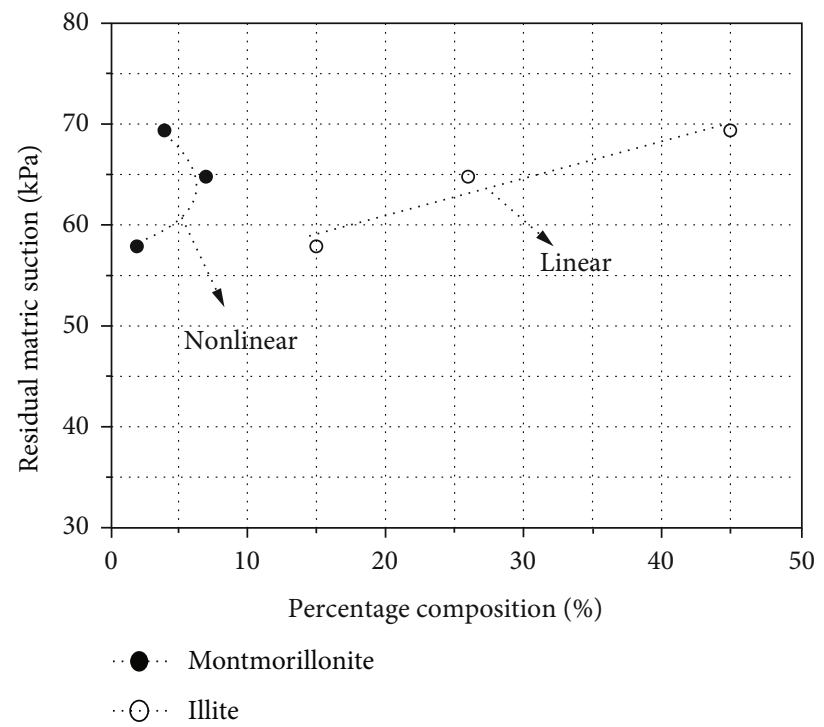

Figure 10: Relationship between metric suction content and content of clay fraction.

was used to fit each SWCC curve, as shown in Figure 4. At the same time, Table 5 shows the corresponding fitting parameters, and the variation curve of each parameter with the net vertical stress is shown in Figure 11.

As can be seen from Figure 11, parameter 1/a increases exponentially with the change of clay fraction content. Both $n$ and $m$ decrease with the increase of clay fraction content, and $n$ decreases linearly with the increase of clay fraction content, indicating that the water storage coefficient of soil decreases in an exponential form. $m$ decreases in the form of a negative exponential with the increase of clay fraction content, and it can be seen that when the clay fraction content exceeds a certain value, the rate of decrease increases significantly.
3.3.2. Influence of Montmorillonite Content on Soil-Water Characteristic Curve. Figure 12 is the SWCC curve of unsaturated clay foundation soil with different montmorillonite contents in the test section. It can be seen from the figure that the water content of soil decreases with the increase of matric suction under the effect of the same montmorillonite content. When the suction is constant, the moisture content of soil decreases with the increase of the content of montmorillonite. At the same time, the V-G model can also be used for a good description. The fitting parameters of the modified van Genuchten model under different montmorillonite content conditions are shown in Table 6 , and the variation curves of each parameter with montmorillonite content are shown in Figure 13. 


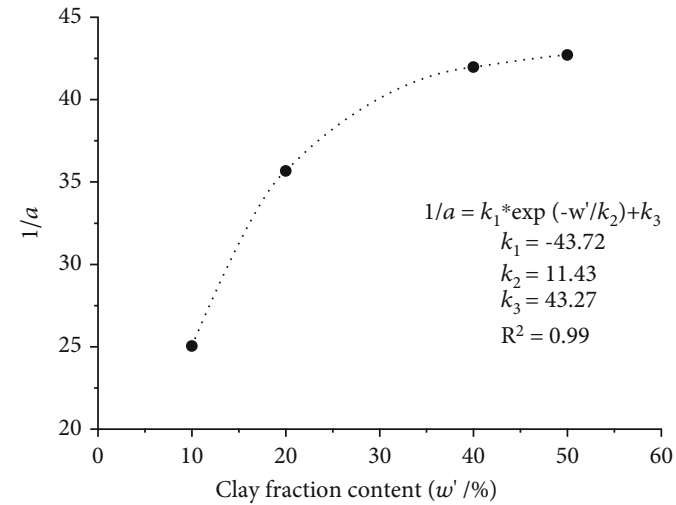

- Experimental value

.. Exponential fitting curve

(a) Relationship between parameter $1 / a$ and clay fraction content

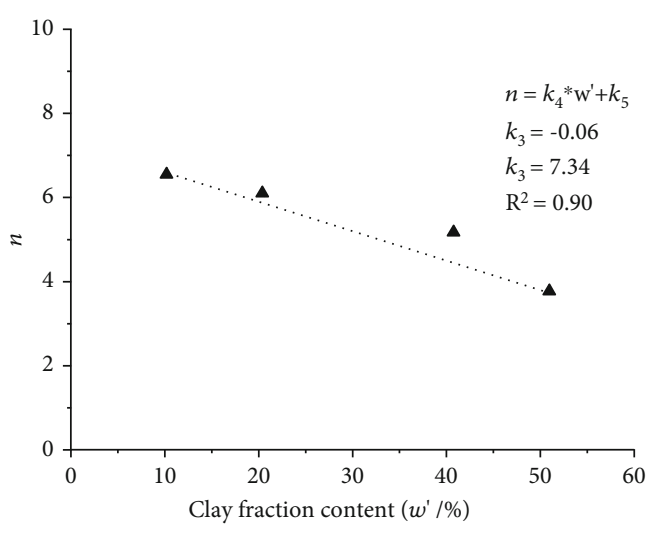

- Experimental value

..... Linear fitting

(b) Relationship between parameter $n$ and clay fraction content

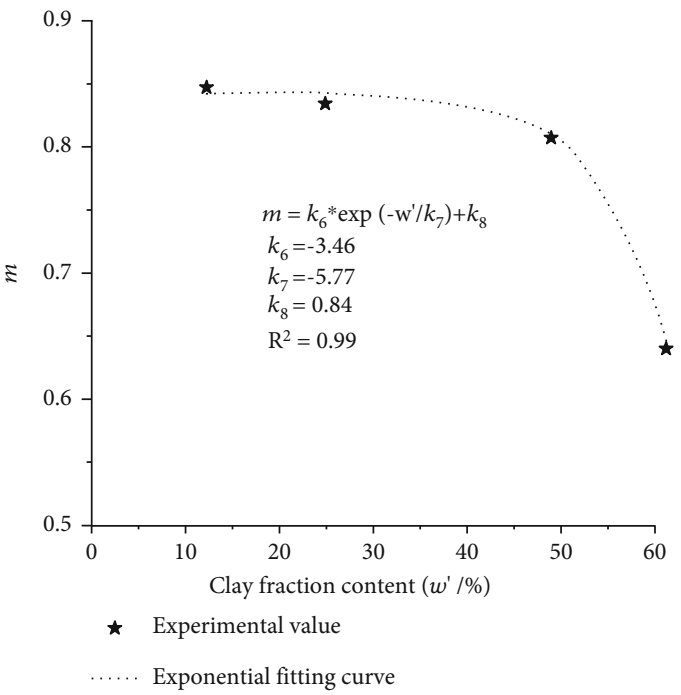

(c) Relationship between parameter $m$ and clay fraction content

FIGURE 11: van Genuchten model parameters vary with clay fraction content.

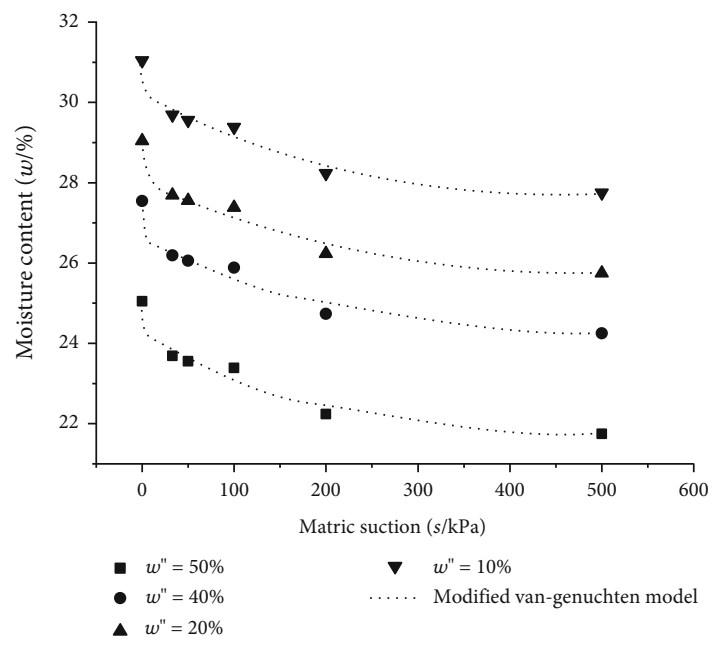

FIGURE 12: SWCC curves of different montmorillonite contents.
TABLE 6: Fitting parameters of the van Genuchten model modified with different montmorillonite contents.

\begin{tabular}{lccc}
\hline Content of montmorillonite $w^{\prime \prime}(\%)$ & $1 / a$ & $n$ & $m$ \\
\hline 10 & 24.78 & 6.524 & 0.842 \\
20 & 38.64 & 5.680 & 0.826 \\
40 & 40.30 & 2.241 & 0.576 \\
50 & 44.22 & 1.224 & 0.192 \\
\hline
\end{tabular}

As can be seen from Figure 13, parameter 1/ $a$ increases exponentially with the change of montmorillonite content. $n$ decreases linearly with the increase of montmorillonite content, while $m$ decreases exponentially with the increase of montmorillonite content. Parameter $n$ is related to the pore distribution size of unsaturated soil. Meanwhile, parameter $n$ reflects the slope of a straight line segment in SWCC, and the slope of a straight line segment in SWCC reflects the water storage coefficient of unsaturated soil. 


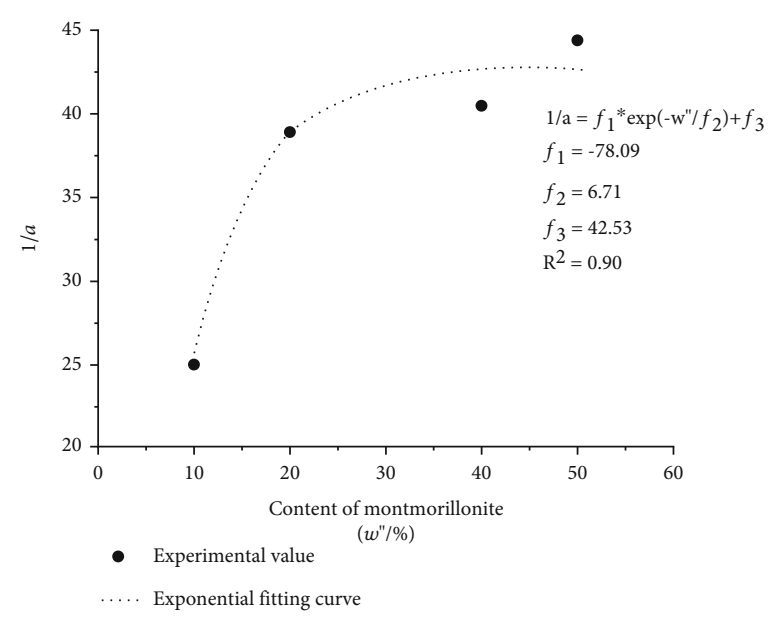

(a) Relationship between parameter $1 / a$ and montmorillonite content

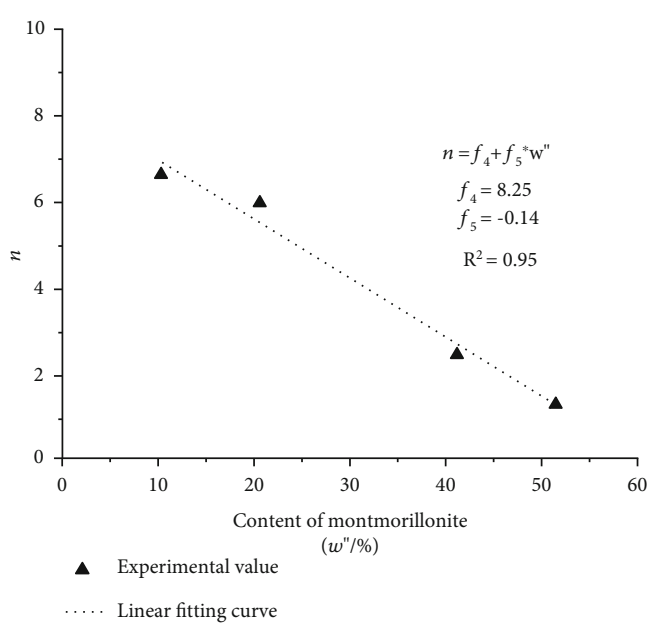

(b) Relationship between parameter $n$ and montmorillonite content

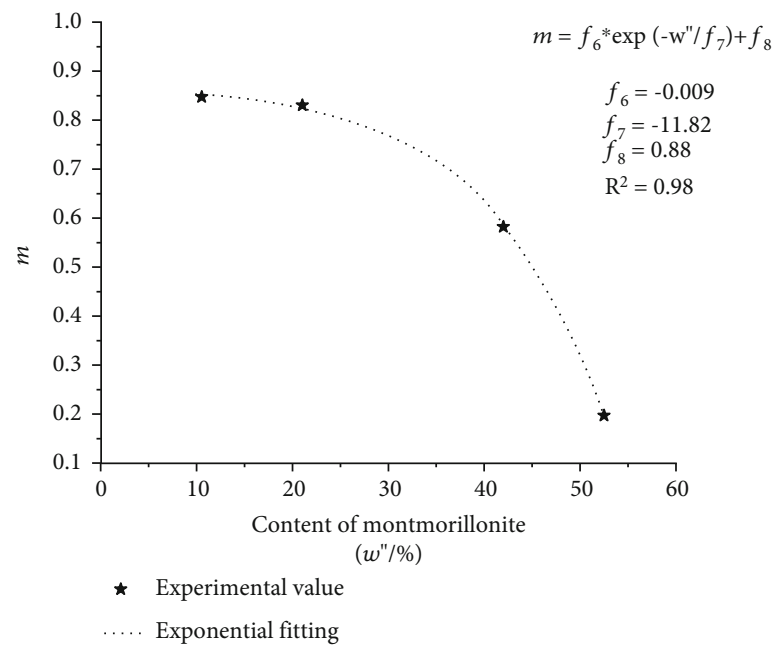

(c) Relationship between parameter $m$ and montmorillonite content

FIGURE 13: The relationship between van Genuchten model parameters and montmorillonite content.

Therefore, it can be seen that the water storage coefficient of soil decreases exponentially with the increase of the content of montmorillonite. Parameter $m$ is related to the asymmetry of the model. With the increase of montmorillonite content in unsaturated soil, the macroscopic pores of the soil will decrease, while the microscopic pores will increase accordingly, and the average pore size of the soil will decrease.

\section{Conclusions}

In this paper, the effects of mineral composition on unsaturated properties of foundation soil in the test section are analyzed by two kinds of laboratory tests. Through the research, the following conclusions are obtained.

(1) The residual water content of soil has a good correlation with the clayey or silt content in gradation and has a significant positive linear correlation with the clayey content, while a negative linear correlation with the silt content
(2) Residual matric suction has a nonlinear correlation with clay or silt content in gradation, in which it has a significant negative nonlinear correlation with clay content and a positive nonlinear correlation with silt content

(3) The residual water content and the residual matric suction have an obvious linear relationship with the content of montmorillonite in the foundation soil but have no obvious correlation with the content of illite

(4) The water-storage coefficient of unsaturated airfield foundation soil decreases exponentially with the increase of clay content and montmorillonite content

\section{Data Availability}

The figures presenting the test data analysis were all drawn in AutoCAD 2019, Origin 8.0, and Midas/GTS. The data are available and explained in this article. Readers can access 
the data supporting the conclusions of this study. Also, all the data files used to support the findings of this study are available from the corresponding author upon request.

\section{Conflicts of Interest}

The authors declare that they have no conflicts of interest.

\section{Acknowledgments}

We gratefully acknowledge the 2021 Open Project of Failure Mechanics and Engineering Disaster Prevention, Key Lab of Sichuan Province, No. FMEDP202110.

\section{References}

[1] F. Y. Liu, X. Lin, and J. Wang, "Influence of p article-size gradation on shear behavior of geosynthetics and sand interface," Chinese Journal of Rock Mechanics and Engineering, vol. 12, pp. 2575-2582, 2013.

[2] H. H. Fan, G. W. Zhao, and H. L. Li, "Current researches and prospects of dispersive clay," Rock and Soil Mechanics, vol. S1, pp. 108-114, 2010.

[3] L. I. Zhi-qing, H. U. Rui-lin, W. A. Li-chao, and L. Zhi-xiang, "Study on SWCC of unsaturated expansive soil," Rock and Soil Mechanics, vol. 5, pp. 730-734, 2006.

[4] L. I. Zhi-qing, L. I. Tao, and H. U. Rui-lin, "Property of soilwater characteristic curve for unsaturated soil," China Journal of Highway and Transport, vol. 3, pp. 23-28, 2007.

[5] Y. F. Lu, G. F. Chen, X. Q. Luo, and Y. J. Cui, "Study of soilwater sharacteristical surve and its influential factors," Rock and Soil Mechanics, vol. 9, pp. 2481-2486, 2008.

[6] X.-w. Liu, L.-j. Chang, and X.-r. Hu, "Experimental research of matric suction with water content and dry density of unsaturated laterite," Rock And Soil Mechanics, vol. 11, pp. 33023306, 2009.

[7] J. Feng, Y. Ma, and Z. Liu, "A study on the creep characteristics of airport viscous subsoil based on unsaturated stress level," Geofluids, vol. 2021, Article ID 6667245, 13 pages, 2021.

[8] J. Feng, X.-y. Wu, B.-1. Zhu, and Q.-x. Yang, “Analytical solution to one-dimensional consolidation in unsaturated soils under sinusoidal cyclic loading," Journal of Central South University, vol. 22, no. 2, pp. 646-653, 2015.

[9] L. Liang, L. I. Xingwang, and Z. H. Lianheng, "Factors analysis of subgrade stability due to rainfall infiltration," Journal of Railway Science and Engineering, vol. 4, pp. 19-23, 2007.

[10] C.-a. Zheng, "Expansive soil slope stability analysis affected by many factors," Journal of Railway Science and Engineering, vol. 1, pp. 82-86, 2014.

[11] Z. Q. Zhang, C. Liang, and H. Q. Liu, "Study on characteristic curve of unsaturated soil of Yellow River levee," Yellow River, vol. 6, no. 6, pp. 17-18, 2005.

[12] B. Wen and Y.-q. Hu, "Effect of particle size distribution on the metric suction of unsaturated clayey soils," Hydrogeology and Engineering Geology, vol. 6, pp. 50-55, 2008.

[13] D. G. Fredlund and A. Xing, "Equations for the soil-water characteristic curve," Canadian Geotechnical Journal, vol. 31, no. 4, pp. 521-532, 1994.
[14] Z.-h. Chen, "Deformation, strength, yield and moisture change of a remolded unsaturated loess," Chinese Journal of Geotechnical Engineering, vol. 21, no. 1, pp. 82-90, 1999.

[15] E. E. Alonso and A. Gens, "A constitutive model for partially saturated soils," Geotechnique, vol. 40, no. 3, pp. 405-430, 1990.

[16] Y. Mualem, "A new model for predicting the hydraulic conductivity of unsaturated porous media," Water Resources Research, vol. 12, no. 3, pp. 513-522, 1976.

[17] Y.-S. Song, H. WoongKi, and T.-H. Kim, "Construction and application of an automated apparatus for calculating the soil-water characteristic curve," The journal of Engineering Geology, vol. 20, no. 3, pp. 281-295, 2010. 